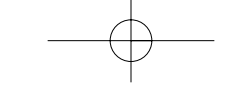

\title{
10
}

\section{Restructuring Gendered Flexibility in Organizations: a Comparative Analysis of Call Centres in Germany}

\author{
Ursula Holtgrewe
}

\section{Introduction}

Telephone call centres are represented as the less skilled and externally flexible segment of the new economy. They are frequently cited as an exemplary case for neo-Taylorist standardization and automation of service work, where tasks are simplified and jobs are poorly paid and insecure. Through such a downgrading of working conditions, companies achieve numerical flexibility. This pattern has often been gendered, especially in computerized service and clerical work. A gendered segmentation of tasks and workforces has been a way for companies to legitimately become more numerically flexible. Especially in coordinated economies, part-time work plays a crucial part in the gendering of flexibility (cf. Nishikawa and Tanaka in this volume). The equation of downgrading, de-skilling and feminisation may possibly be reiterated in call centres, another instance of ICT-supported flexible information work. Yet empirical findings suggest that call centres do not simply re-enact a Taylorist logic of rationalization and that in this new field heterogeneous patterns of gendering apply. ${ }^{1}$

Call centres are companies or organizational units which specialize in customer contact over the phone supported by networked information and communication technology. Call centres embody both a logic of standardization and a logic of service quality and customer orientation, in which rationalization is both enhanced and limited by the flexibility and indeterminacy of communications. While historically (starting with the early telephone operators) women have often been employed in jobs that were new, rationalized and concerned with compensating the limitations of new technology, this chapter argues that with the use of call centres, companies restructure the traditional arrangements of gendered flexibility, recombining diverse workforces and human resource practices.

In German call centres, we observe a differentiation of gendering processes. In lower-skilled call centres such as mail order the neo-Taylorist patterns of de-skilling and feminization are continued. In small and medium 
enterprises (SMEs) we find a different, more functionally flexible pattern of women's employment, which has been typical of clerical work. In small marketing call centres, skilled women part-timers accept flexible working time schedules and fairly low remuneration, but take over a range of enriched tasks ranging from call handling to project management. In the maledominated areas of call centre work such as technical hotlines and financial services, traditionally masculine notions of skill are being recast - in opposition to the feminized and emotional labour image of call centre work. A new pattern in which gender loses its relevance is found in banks in Germany. In the banking industry students are hired regardless of gender and in the place of skilled female part-timers. Thus, flexibility comes to be redefined in terms of dynamism and knowledge work.

This differentiation suggests that business organizations in certain industries face the tension between an increasingly market- and knowledge-driven 'new economy' and a changing gender regime and seek to increase and extend their strategic options in and through these changes. Theoretically this chapter aims to emphasize and explore the role of organizations in between both emergent and strategic, path-dependent and transformational changes in economies and gender regimes.

\section{Gender, restructuring and organizations}

\section{Call centres and the new economy}

Call centres can be regarded as part of the new economy for several reasons. To begin with, call centres make intensive use of ICTs, connecting telecommunications and computer technology, and technology is used to relocate work in time and space. Call centre operations may be outsourced, shifted to greenfield sites outside the purview of established industrial relations institutions and collective agreements, and routed through networks of call centres connected by phone and data lines. As in other networked industries, this does not mean that space becomes irrelevant but that the 'delocalising potential of new ICT ... makes the characteristics of locations even more important' (Huws 2003: 58; cf. Castells 1996, passim). Call centres tend to be located where a suitable workforce for their respective service can be found. In Germany as elsewhere (Belt et al. 2002), that is often in metropolitan, but de-industrialized areas such as Bremen, Hamburg, Berlin/Brandenburg or the Ruhr area with a high availability of students, or in the case of simpler services, in the East German regions where the lack of alternative employment keeps labour turnover down (Arzbächer et al. 2002; Arnold and Ptaszek 2003).

Call centres also represent a general reshaping of customer relations and modes of consumption. Organizations using call centres do not just offer an additional channel of communication, but try to generate new knowledge and operate strategically upon the information they have and can gather. 


\section{Gendering New Employment Forms}

Computerized data mining, for example, searches for actual and potential patterns of consumption in customer databases and thus generates knowledge about possible customers and sales prospects. Such prospects can then be pursued by outbound calling. Part of a CSR's (customer service representative) interactive work in such cases is to get a customer to cooperate with and tie herself into an organization's routines, and even to take over some of the work which had previously been done in the organization. Technical hotlines and customer information services operate recursively on the limitations and consequences of ICT use. Computer technology enables products, services and prices to be differentiated and customized in such a way that self-service over the internet must be complemented or supported by the more flexible articulation of IT, communication and expertise that call centres provide.

In terms of temporal reorganization, the flexibility that call centres provide is clearly market-driven. The interactive character of call centre work requires working times to be closely tied to customer demand. Call centres are used to increase service times up to 'round the clock' availability, though in some cases 24-hour, seven-days-a-week operating times were found to be exaggerated in relation to customer demand. Staff shortages or overstaffing become immediately visible through the data generated by automated call distribution systems which note idle times and 'calls lost'. Consequently, shift patterns and working time arrangements tend to be highly sophisticated, often supported by computerized planning and scheduling systems. In addition, the willingness of CSRs to change their working schedules at short notice is often included as a performance measure in appraisal systems. Employment contracts (and also collective agreements, where they exist) increasingly cover flexible 'working time accounts' based on a corridor of hours per week or month to eliminate overtime pay. On the other hand, within the parameters of a company's forecasting of call volumes, many employees can exercise considerable discretion to choose their own schedules - even where working conditions are otherwise tightly regimented. As will be demonstrated below, particular types of call centre services place different demands on workers' temporal flexibility, which in turn plays an important part in the gendering of call centre workforces.

As regards knowledge work, call centre workers are found at the boundaries of types of knowledge - 'on the front line' as Frenkel et al. have aptly put it (1999). Interacting with customers, they translate contextualized demands and problems into encoded knowledge bases and vice versa indeed, they do the encoding and embraining of knowledge (cf. Durbin in this volume; Lam 2002) on behalf of the organization. Since speech is the tool of their trade, they represent an interesting contrast with Nishikawa and Tanaka's care-workers (in this volume): a certain explication of knowledge is essential, and this is work performed by both customers and CSRs. Yet this does not necessarily lead to CSRs' professionalization (i.e. a codifi- 
cation of their skills), but rather to a combination of intense use of information technology to both support and control work, an intense use but not necessarily a recognition of skill, and considerable efforts that call centres put into training. Thus, call centres illustrate the need to consider not just knowledge types but the shifts and translations between types of knowledge in analysing knowledge work and organization.

In sum, call centres are representative of a key aspect of the 'new economy': how 'modern ICTs widen the range of organizational options available to companies' (Huws 2003: 65) and open up space for organizations to strategically act upon a number of aspects of the firm's environment: labour markets, customer relations, competition, institutional regulation, etc. However, the increased strategic options also make it necessary for companies to act upon them. These options may be structured by the path-dependencies of specific varieties of capitalism (Hall and Soskice 2001), but they may also offer opportunities for change.

Yet call centres do not fit comfortably into the knowledge-based sectors of the economy, since they are established in various organizational configurations and in various industries and sectors. They range from specialized service firms to in-house departments, and from public administration and health through retail, financial services and telecommunications to manufacturing. So far, there is no internationally viable way of counting call centres and call centre jobs, though a large segment of call centres belongs to the OECD's 'knowledge-intensive service sector' (Shire in this volume).

Obviously, the discussions of the new economy, the network or knowledge society do not just address changes in social structure and work organization. Like gender (Acker 2003) or social relations in general (Giddens 1984), they also have a strong symbolic and legitimatory dimension. On the symbolic level, call centres draw on the semantics of the new economy which describes itself as constitutively innovative, knowledge-based and immaterial. As new, recently established organizations, they present themselves as innovative and are generally perceived in this way. Norms and expectations of innovation in turn legitimize change.

The dimensions of signification and legitimation, however, do not just mirror and legitimize structural changes. Neither can structural changes be explained through the performativity of discourses exclusively. Indeed, empirically, we observe some differentiation between 'talk' about and structural changes of gender relations in call centres. In order to account for such loose couplings and differentiations between the discursive and the structural, I borrow the concept of semantics from the tradition of German systems theory (Luhmann 1980). Semantics mean generalized repositories of meaning which social systems draw upon to describe themselves and to ascribe actions and decisions. For gender relations, equality and difference present semantic fields which are of interest here. In work organizations, rationality, market demands, performance and skill are important. For call 
centres specifically, service and knowledge, expertise and customer-orientation come to mind. In the systemic view, both social structures and semantics evolve separately but are interrelated. In most cases, the evolution of social structures takes historical and analytical precedence (Stäheli 1998) because a structure needs to be in place in order to be made sense of. Stichweh (2000) argues, however, that changing semantic fields and concepts may precede or facilitate structural changes. At any rate, the concept keeps the actual relationship of the structural and the symbolic open to empirical investigation. From a feminist point of view, however, it is important to bear the inherently conflictual character of social self-descriptions in mind, which is somewhat alien to the orthodox Luhmannian terminology. Viewed in terms of semantics, 'knowledge' in its diverse forms is not just a resource for organizations and individuals. Its recognition and valuation in organizational talk and action become the site of both discursive and material struggles between workers and organizations, between management factions, professional groups, and also between men and women (cf. Durbin in this volume).

\section{Call centres as specifically flexible organizations}

From an organizational perspective the establishment of call centres is part of organizational strategies to comprehensively design their relations and communications with customers. Call centres are boundary-spanning units, i.e. units specializing in communicating with an organization's environment. Their specific environment is customers or clients who are strategically central for any business organization. The needs and demands of customers are processed and articulated with a company's offerings, and the point of selling and marketing strategies is to influence customers' demands and preferences to fit with products and services. Here, connections between information and communication technology are used to both standardize and diversify products and services, to flexibly bundle and segment customer groups, to gather information about customers and influence them to cooperate with the organization. All of these functions tie in with one another, and organizational and technological means are put to work by and through CSRs' communicative skills and flexibility in customer interactions. This boundary-spanning function is the reason why call centres cannot follow an unambiguously (neo-) Taylorist logic of rationalization. Such a logic is counter-balanced by the logic of organizational flexibility and the capacity to react to market and customer changes. At the boundaries of organizations this balancing act takes place both in management and in everyday work (Frenkel et al. 1999; Korczynski 2001, 2002; Holtgrewe and Kerst 2002a, 2002b; Kerst and Holtgrewe 2003).

Hence in call centres we observe the 'construction of flexibility' (Arzbächer et al. 2002) on multiple levels. Institutionally, call centres are often established outside of traditional collective agreements, regulations and tradi- 
tional HRM policies. Workforces and human resource practices are recombined and temporal and interactive flexibility is managed on an everyday level. As we shall see, this comprehensive and multilayered flexibility addresses gender relations as well, flexibly articulating 'old' and 'new' patterns of flexibility.

\section{Gender, skill and organizational flexibility}

Traditionally, organizational flexibility has been centrally, but not deterministically structured by gender regimes while structuring gender regimes and gendered institutions in turn. This view would suggest the development of path-dependent patterns of flexibility in which institutionally and culturally embedded gender contracts are reproduced or changed incrementally (Smith and Gottfried 1998; Gottfried 2000; Pfau-Effinger 2000).

At first glance, call centres draw on women's work in a pattern that is familiar and almost traditional in service and clerical work (Game and Pringle 1984; Gottschall et al. 1985; Gottschall et al. 1989; Webster 1996): starting with telephone exchanges, then typing, data entry, typesetting or clerical work, the routinization and rationalization of work has been linked historically with its feminization. Women in such jobs however, are mostly not unskilled, but rather have some level of general education and/or occupational training. Thus, the feminization of routinized work combines the advantages of numerical and functional flexibility. If routinized work is done by skilled women with limited labour market options, their skills need not be recognized but are kept in reserve to compensate for the very problems and side-effects of rationalization. Organizational flexibility is achieved through women workers' skill reserves and downward flexibility. Juliet Webster for example points to the continuity in the supposedly new patterns of flexibility:

There is strong evidence that forms of employment now being hailed as flexible are in fact long-established patterns of labour market exploitation with which women workers are all too familiar. Institutionalised and legitimated as flexibility they may simply serve to confirm and extend the appalling working conditions of millions of working women, with the low pay, lack of employment protection, lack of equal opportunities and career prospects and insecurity which is commonplace in women's work. (Webster 1996: 84)

Most recent research addressing gender relations in call centres also sees a reproduction of the pattern of flexibility as the devaluation of women's work (Belt et al. 2002; Krenn et al. 2003; Durbin in this volume).

Other authors, however, argue more generally that changes in gender and in employment relations are not or no longer unidirectional. The gendered and gendering effects of skill, security, standard employment and labour 
market segmentation are beginning to differentiate with women acquiring improved qualifications and attempting to participate continuously in the labour market. These interrelations depend all the more on a society's respective institutional context, as various authors pointed out throughout the 1990s, as well as on women's culturally and biographically embedded decisions (Rubery and Fagan 1994; Flecker 2000; Pfau-Effinger 2000).

De-regulation thus does not necessarily lead to a coherent pattern of flexibility, nor is the feminization of the labour force by any means naturally connected to labour market flexibility. Sylvia Walby (2002a, and in this volume) argues that taking gender relations into account, increasing flexibility should not be mistaken for wall-to-wall de-regulation. While market forces are gaining ground in processes of globalization, gender regimes are changing in the direction of increased regulation by nation-states and the European Union - so that institutional changes often operate in tense and contradictory relations. The question of path-dependency (Gottfried 2000) versus the transformation of previous paths thus needs to be addressed empirically.

The case of call centres suggests that in certain contexts, organizations may strategically break away from such path dependencies. Call centres represent a genuinely 'new economy' widening of organizational options, a possible escape ${ }^{2}$ for companies from traditional labour relations. We shall see that the recruitment and HRM practices of call centres in Germany do not simply reiterate the traditional pattern of downwardly flexible women's work. Flexibility itself is being restructured - and the mode of flexibility is not just shaped by national and transnational institutions but also by the contexts of particular industries and organizations. Especially the case of German banks points to the construction of a flexible relationship of organizations and specific industries with society-wide institutional gender regimes. Flexible organizations flexibilize work beside and beyond the established gendered patterns of flexibility. Flexibility is decoupled from gender when new transitory workforces become available - while, as we shall see, the semantics of skill and dynamism reiterate fairly traditional gender distinctions.

\section{Flexibility and organizations}

All these lines of argument suggest that flexibility addresses gender relations and regimes and that it can be expected to move in contradictory patterns. I argue that in such processes of institutional change, the actual development of these contradictions, inequalities and temporal imbalances is best explored on the level of industries and organizations.

Theoretically, the concepts of gender regimes and contracts structuring the gendering of work and employment patterns often imply a neoinstitutionalist outlook with a focus on organizations following norms and expectations, isomorphically adapting to regulations, norms or professional 
standards (Powell and DiMaggio 1991; Scott 1995). On the other hand, organizations, especially business organizations, are the collective actors who centrally articulate and shape the work and employment side of gender regimes. Organizations design jobs and hierarchies (Acker 2003), employment relations and HRM strategies and they utilize particular labour forces (Jenkins 2004). Doing this, they do not just enact gendered labour markets, societal institutions and cultural images. Rather, they actively act upon them, both strategically and by default (Jepperson 1991). It is thus on the level of work organizations that the described tensions between marketled de-regulation and flexibility on the one hand, political regulations and social norms of equality on the other, are being processed, and this processing happens in a strategic way. For example, organizations implement equal opportunity policies, select among available 'tools' and aims, or seek to escape or avoid such expectations and demands. Evidently, however, they are neither totally adaptive to their environment nor omnipotently rational and strategic. Both enactment of and strategic action upon gender regimes and gender relations take place in organizations' respective contexts and environments: labour markets, welfare states, cultural expectations, regions, industries, networks, etc. (Tienari et al. 1998; Quack and Morgan 2000a, 2000b).

Conceiving of both aspects, adaptation and strategy, as parts of a recursive loop results in a structurationist (Giddens 1984) model of institutions, cultures and societies both enabling and restricting actors' capacity to act, i.e. to reproduce and/or transform social relations (Ortmann and Sydow 2001). And in this model the organizational fields, the actors, rules and resources in the field and the actors' strategies mutually constitute one another (Friedberg 1995). Where and when gender (or age, ethnicity, experience) matter, what service, quality and skill actually are - all of this is enacted and may be negotiated in the organizational field in question.

Call centres should thus be explored as an organizational field in which new and old features combine and articulate. On the 'new' and transformative side of these changes are the strategic centrality of knowledge, customer relations and flexibility, the interlaced organizational design of customers, products, services and structures, and the semantics of the new economy and innovation. These new features are nonetheless met with the persistence and/or path-dependent development of traditionally gendered labour markets and careers and of gendered constructions of skill and expertise.

\section{Re- and de-gendering work in call centres}

\section{Call centres in Germany: managing flexibility}

The German call centre sector has been expanding beyond operator services, mail ordering and direct marketing since the mid-1990s with some consolidation since 2000. The first direct bank (the former Bank24) started 
operations in autumn 1995. The development was triggered by interrelated technological and institutional factors which converged in the mid-1990s. The liberalization of telecommunication and energy markets, the strong growth of mobile telecommunication and the diffusion of internet access into private households led to the emergence of new markets, new packages of goods and services, new types of customers and new information needs (Arzbächer et al. 2002; Bain and Taylor 2002). Currently (in March 2006), there are roughly 280000 people employed in German call centres. The question of gender relations in call centres has only begun to be addressed (Bialucha-Rhazouani 2002; Holtgrewe 2003; Kutzner 2003), possibly because gender researchers have expected to simply reconfirm the all-too-familiar processes of de-skilling and downgrading. ${ }^{3}$

In call centres, the overall majority of workers are women, yet call centre work is not exclusively women's work. Most studies find that on average two-thirds of call centre agents are women, with the degree of feminization varying from 90 per cent in direct marketing and mail ordering services to 50 per cent in technical hotlines across different national contexts (Belt et al. 2002; Bittner et al. 2002). Part-time employment rates in German call centres are generally put between 40 and 50 per cent with wide variation between types of call centres. Higher-skilled and in-house call centres rely on higher proportions of full-time employees. ${ }^{4}$ Apart from women returning to work who work part-time, university students and both male and female full-time workers also make up the workforce in call centres (Bittner et al. 2002). Workforces tend to be young with at least a third of all CSRs under 30 years of age and three-quarters under 40 . In the sample of our own call centre survey (five call centres, 491 agents), 28.1 per cent of all agents worked full-time, 46 per cent of who were women. Part-time workers who were not students comprised 27.9 per cent of the surveyed workforces with 86 per cent of such part-timers being female. University students comprised 44 per cent of call centre workers. Among the students, women and men were equally represented. The proportion of students in our study is higher than in other studies, because students are concentrated in banking call centres. Full-time workers were chiefly found in in-house call centres, which had typically taken over workers from other functions of the company organizations. Women part-timers mainly worked in outsourced call centres and in call centres where tasks with lower skill requirements were common. Parttime work in call centres overall, however, was fairly extensive, with an average working time of 20 hours per week. ${ }^{5}$

\section{Call centre workforces}

Call centre labour markets are segmented along both old and new lines, which are related to working time and availability rather than directly to gender. The norm of flexibility is central since the deployment of workers in call centres is connected as tightly as possible to shifts in call volumes. 
In our study we found three distinct types of workforces (cf. Kerst and Holtgrewe 2003) where processes of gendering and undoing gender can be observed. These types will be illustrated here with evidence from our case studies.

(1) In lower-skilled call centre work such as mail ordering, the neo-Taylorist pattern was retained. These call centres favoured women part-timers with unspecific service qualifications, with the expectation that these women would comply with restrictive working conditions and emotional labour demands.

(2) We also found a pattern of women's employment which has been typical of clerical work in small and medium enterprises. In small marketing call centres, skilled women part-timers accepted flexible working time and fairly low remuneration, but took over a range of tasks reaching from call handling work to project management.

(3) Banks have moved away from the traditional pattern of routinizing clerical work by employing skilled women part-timers. Instead they hired students regardless of gender, thus decoupling flexibility from gender and recasting it in terms of knowledge work and the need for a dynamic workforce.

While both of the first two workforce patterns reiterate traditional patterns of gendered employment in Germany, the third pattern found in the banking industry is new. Here flexibility has indeed been redefined. Whereas traditionally, numerical and functional flexibility have been optimized by recruiting skilled women for deskilled part-time work (Gottschall et al. 1985; Jenkins 2004), what we currently find in German banking call centres is a de-gendered articulation of functional and numerical flexibility guaranteed by the transitory status of students.

\section{Neo-Taylorism in mail ordering}

The mail order call centre we studied handled orders and enquiries from private customers of a teleshopping TV channel. Of the 500 CSRs, all worked part-time and 75 per cent were women, most of whom had previous occupational training and experience in customer-contact jobs. The centre had fairly restrictive working conditions, low wages and a very flexible shift system according to which CSRs were employed in three groups corresponding with different planning horizons (Holtgrewe and Kerst $2002 \mathrm{~b})$. The recruitment of female part-timers had been the result of a homogenization of the workforce over time. A works council member reported that the share of students had been decreased from around 90 per cent to 40 per cent at the time of our research since students were harder to discipline. 
When we started here [in 1998, U.H.] there were almost only students, 90 per cent. Meanwhile they don't really want them anymore. They don't take so much nonsense. They don't care... (mail order1, works council member, translation U.H.)

This call centre complemented its neo-Tayloristic standardization of work with nostalgic attempts to reconstruct the friendliness and closeness to the customer of traditional retailing businesses. Agents reported receiving much appreciation from their customers, who tended to be elderly people from lower income groups: 'you don't get that friendliness in department stores nowadays' (mail order1, agent, translation U.H.). While customer interactions were scripted and strictly supervised, friendliness and empathy were inculcated in communication trainings. Workers also drew on previous experience in service jobs which were often close to the working-class habitus of their customers, for example as taxi drivers, parttime pub landladies or sales workers in the small corner shops typical of the region.

In this type of call centre employment, the combination of normative appeals and restrictive working conditions continued the alliance between rationalization and emotional labour which has been recurrently observed in retailing by authors such as Siegfried Kracauer in the 1920s, C. Wright Mills in the 1950s, and most recently by Barbara Ehrenreich (Kracauer 1929/1971; Mills 1953/1971; Ehrenreich 2001).

\section{Job enrichment in marketing}

The second pattern of women's work which is specific to SMEs in Germany (cf. Gottschall et al. 1989) is represented in the example of a small marketing call centre with 26 agents which specialized in supporting business-to-business sales. The job in this centre typically consisted of identifying prospective buyers of investment goods and making appointments for the sales staff of the call centre's clients. The enterprise pursued a clear quality approach, emphasizing the reliability of pre-sales research. At the time of our interviews, the workforce was exclusively female and part-time, although occasionally men were employed. Working times mostly fell into the nine-to-five range since prospective customers were contacted during normal office hours. The owner preferred to employ mature people returning to work with experience in clerical or sales occupations. One of the team leaders we encountered held a pre-1991 East German engineering degree, a qualification specifically devalued since reunification. In this call centre, CSRs also took over project management tasks. This configuration of the work and employment structure falls in line with the practices of other small and medium enterprises. We found a profile of a skilled female workforce who were not supposed to turn up their noses at simpler call handling tasks, yet at the same time 
were capable of and encouraged to take up more complex work. From the workers' point of view, the comparatively low wages were compensated by interesting work and by the cooperative and familiar relationships with co-workers and supervisors.

\section{Banks I: decoupling gender and flexibility}

Banking call centres are the type that departs from established gendered (and gendering) patterns of employment. At the start of our study, we expected banking call centres to continue patterns of de-skilling the work of women returning to work part-time. Yet we found that the demand for flexibility by the banking industry outpaced the flexibility supplied by female part-time workers. Women returning to work part-time tend to be mothers, and their preference for working times that suit school hours (half-day in Germany) places limits on their working time flexibility. Banks have responded to these limitations by employing fewer female part-time workers over time. Also in terms of habitus, students appear more mentally agile to personnel managers as indicated by one general manager:

In the beginning, we had many housewives and mothers in there... but with increasingly complex tasks in the call centre it gets difficult. The longer the working time, the better the knowledge is present for us, and mental flexibility - there's nothing wrong with housewives, but students are of course quite differently involved and are better able to react in this fast-moving industry we're in and to attune to that. That has had the effect that now we hardly hire anyone who is not studying. (Bank3, CC general manager, quoted from Bialucha-Rhazouani 2002: 63f.)

Banks are thus departing from the traditional divisions of labour in cases where temporally and habitually more and differently flexible workers are available. According to some accounts, for some time banking call centres practised a norm of mixing together diverse groups of workers (cf. Belt 2002), but as soon as flexibility took on the semantic connotations of the 'new economy' and its dynamism, women with banking qualifications became perceived as housewives and mothers. The interpersonal skills they had ascribed to them fell into disregard. Students working parttime offered a new and attractive type of skilled transitory workforce. Students have skills which are not yet certified, they have practice in the rapid acquisition of knowledge and also in impression management, i.e. sounding competent even if they are not. They are also able to work at unusual hours, and they can afford to have limited aspirations in their current jobs. Plus, importantly, they perceive call centre work as a learning opportunity to acquire the kind of service and communication skills that are not taught in universities. 


\section{Banks II: asserting masculinity}

While the recruitment of the general CSR workforce became increasingly gender-blind in banks, and the ascription of interpersonal skills to women was rendered irrelevant, hegemonic masculinity was asserted both in terms of management and technical expertise. In recruiting for supervisory and management positions, banking call centres favour full-time workers. These recruitment patterns have less to do with functional necessities, since supervisors are not in charge of fixed groups and teams, and more to do with the norms and the semantics of flexibility:

Managers are on principle expected to be endlessly flexible. That's just a matter of attitude. If I say as a manager, I can only come to work three days a week and I have to motivate people to be flexible and to actually live the capacity planning - that's leadership by example. (Bank1, general manager, translation U.H.)

'Endless' flexibility addresses availability for work rather than gender directly - but the statement represents a closure of career options for the less-thanendlessly flexible worker. Yet in supervisor and management positions in call centres there is a considerable share of women - figures range from 11 per cent in the study by Kutzner (2003) to 31 per cent (Bittner et al. 2002: 69). ${ }^{6}$

A more explicit reassertion of masculinity is found in those call centres which are dominated by men, i.e. technical hotlines, sales in service call centres and private banking. Here, managers eagerly redefine gender ascriptions by shifting the meaning of skills and competencies. In the field in general, there is a widespread consensus among managers, also reflected in training handbooks, that recruitment needs to focus on employees' social and communicative skills and personality traits. Expert knowledge in contrast can be acquired through learning (Frenkel et al. 1999). Yet in the hotlines, this technical expertise is rated higher (cf. Belt et al. 2002):

It's different with us, and with the colleagues in the hotline it may be even more so. There, you have real computer geeks, and in part, these guys just aren't nice. It's not in their nature. They don't look nice, they aren't nice. But they are brilliant in their field ... That's probably different in other services and certainly in outbound. There, the largest part is friendliness, communicative skills. But in the areas where expertise matters, that's less important. (supervisor Bank1)

This image appears to be slightly overstated. In tasks involving technical problem-solving over the phone, communicative skills are certainly more important than purely technical brilliance, and it is socially quite possible 
for men to be both friendly and competent. From this supervisor's point of view, however, such friendliness would appear almost unprofessional. In a field which is often perceived as feminized and de-skilled, this manager (and others interviewed) defended 'their' men against possible demands for 'unnatural' social skills in the name of technical expertise and a stereotypical image of masculine geek culture. Bialucha-Rhazouani (2002) reports that in sales as well, managers framed social skills in masculine ways, emphasizing assertiveness and tenacity rather than empathy. Hotlines and sales incidentally are those areas in call centre work which pay the highest wages.

While it is not new, but always interesting to observe just how flexible, ambiguous and even contradictory gendered ascriptions and definitions of skill are (Game and Pringle 1984), the question which remains concerns understanding the effects of such articulations of expertise and friendliness. Assigning certain skills to some sectors of call centre work may legitimate social closure against women (Cyba 1998), but it is also possible that women in the field profit from claims to expertise and professionalism as well (and indeed, women working in technical hotlines do claim such expertise).

\section{Recomposing workforces}

In all three cases we find evidence of call centres increasingly identifying their 'ideal' labour forces along the lines of the task structure, the customer market structure and the demands on working time and flexibility of the respective call centre business. ${ }^{7}$ The pattern of employing women parttimers with limited aspirations and options on the labour market and with skills being kept in reserve is thus differentiated. Mail order and other lowend call centres continue, in the Taylorist tradition of combining regimented work and emotional labour, to employ female part-time workers in the established way. The SME model where skilled women are employed 'elastically' in between call handling work and complex project tasks is also continued in the context of call centre work in smaller organizations - leading to a combination of interesting and enriched work with limited remuneration. Both mail ordering services and small call centre businesses continue the paths of labour utilization which their industries of origin have pursued, a consistency reinforced by perceptions of customers' expectations. Banks, however, have discontinued the gendered employment patterns at a time when other flexible groups of workers have emerged and the strategic emphasis is being placed on dynamism and innovation. Notably, bank call centres mostly have comparably favourable working conditions.

The variety of gendering of call centres thus appears to be contingent upon the respective industry and type of service, on the size of the company and - not least - on the degree and focus of a company's strategy shaping the use of call centres. In the cases of the mail ordering and the small business service call centres, traditional gendered employment patterns are retained. They fit with both their industries of origin and with customer 
expectations. Retailing in Germany in general is characterized by a reduction of personnel cost, staffing shortages and increasingly pressurized working conditions in which the contradictory demands of market performance and customer orientation are addressed to employees directly (Voss-Dahm 2003). Service innovation in our case is restricted to the communication channels employed (teleshopping), and this service can be best performed by (a reconstruction of) 'traditional' empathy and friendliness under tight temporal restrictions. The quality-orientation and personalized style of small business marketing is aimed at strategically shaping the market and educating customers about the service quality they require. Such call centres distinguish their service from cheaper, low-end marketing outfits by building trust in their high-quality knowledge of sales prospects gathered on the phone and fed into customers' sales activity records. Workers' low wages are compensated by friendly working relationships and some job enrichment and discretion at work.

Banks pursue the most comprehensively strategic approach to the utilization of call centres: a deliberate escape from traditional industrial relations, organizational hierarchies and customer relations. Greenfield sites are established (frequently remote from traditional banking locations), hierarchies flattened and customers offered fundamentally new services and delivery channels - and in the process, new transitory workforces are discovered.

In sum, in line with the 'optional' concept of the knowledge economy, call centres, ICTs and gendered patterns of flexibility offer companies an increased range of strategic options, which are utilized with varying degrees of path-dependency and transformation of traditional patterns. The more strategic and comprehensive a company's and an industry's approach to call centres, the more flexibly they will draw on specific labour forces and gender regimes, and the more options they will discover in turn. In relation to gendered employment patterns in banking in general, however, these findings are specific to call centres and do not mean that gender is becoming less relevant throughout the industry.

\section{Re-engineering skill in call centres}

Across the cases, call centres with their specifically flexible demands, their non-standard employment patterns and their newness in the employment system represent a departure from the established German system of occupational training. In Germany, clerical and service occupations are to a large extent included in the densely regulated occupational training system with institutionalized apprenticeships combining school and workplace training (Hillmert 2002). Training for clerical and secretarial skills also takes place in upper secondary schools with an occupational rather than academic focus, in which case formal qualifications are regulated by the chambers of commerce. Women participate in the 'dual system' (to a lesser extent than men, Rabe-Kleberg 1993), but tend to be concentrated in clerical and service occu- 
pations. Institutional arrangements in Germany tend to force women into discontinuous careers, and it is often occupationally trained women whose skills become devalued on the labour market by the likelihood of career interruptions. For example, half-day schools and childcare facilities exert considerable institutional pressure on the working time needs of mothers, in turn limiting their labour market options. A look at the private service sector thus requires a modification of Estévez-Abe's (2005) argument that vocational training in coordinated market economies tends to segment occupations and to encourage firm-specific skills to the disadvantage of women. Training in clerical and service occupations tends to be more industry- than firm-specific. Through women's discontinuous careers, their qualifications are then utilized in a more generalized way. Institutional influences and the labour market thus devalue women's skills, and cultural perceptions confound skills with naturally feminine traits. Thus, skilled women represent the traditional source of 'downwardly elastic' flexibility which goes beyond purely numerical flexibility.

Yet call centres represent a re-engineering of skill. Internationally, personnel managers in call centres often claim that, 'particular formal qualifications don't matter'. For recruitment, they rely on tests of interpersonal and communicative skills rather than on training certificates, and subsequently offer extensive training to new CSRs internally (cf. Thompson et al. 2000).

In Germany, CSR skills have only selectively been integrated into vocational training for clerical occupations (Arzbächer et al. 2002), and chambers of commerce offer training courses and certifications. Yet these have mostly been established to guide unemployed workers into call centre jobs. Training here is tied to the changing, post-welfarist management of labourmarket policy and the new rhetorical emphasis on employability rather than to the established system of vocational training (cf. Larner 2002).

A statement of a personnel manager in banking is typical of the changing meaning of both training and skill: 'Qualification comes second, first we need the enthusiasm. The knowledge and all the rest we do internally and then we make this person a very, very tiny, slimmed-down banker' (Manager Personnel, Bank3).

Within a densely regulated system of vocational training such an orientation departs from established definitions of qualifications. Banks indeed try to escape from the careers and expectations connected with their industry-specific vocational training (cf. Vitols 2003). The specific demands of customer contact in the context of changing sales strategies are a lever for this escape. Institutionalized, industry-specific learning and experience is replaced by supposed 'personality' traits and shorter, ad hoc, companyspecific training related to specific products and strategies.

Yet in the call centres in our sample, more than 80 per cent of the CSRs who were not students had completed two or three years of vocational 
training, mostly in clerical and service occupations. The companies' reengineering of skill was thus still based on workers' previous qualifications and experience. Prior qualifications do not disappear and can still be utilized, but they are both devalued and rendered invisible through the new semantics of personality. The aspect of invisibility points to changes in the training system and its institutionalization. The long-term career and mobility promises of a regulated training system based on industry-specific skills (Estévez-Abe et al. 2001) have traditionally been gendered (Smith and Gottfried 1998; Estévez-Abe 2005). If qualification in call centres (and probably other fields of the knowledge economy, cf. Thompson et al. 2000) is de-institutionalized and turned into portfolios of firm-specific, short-term skills and ascribed personality traits, the gender implications for this skill regime are less predictable and will be differentiated according to industry as well as company strategies and contexts. Again, with regard to skill, we may expect increased optionality for companies and thus, increased varieties within and across varieties of capitalism.

\section{Gendered employment and reorganization in banking}

Since banking has been regarded as the 'heartland of gendered bureaucracy' (Tienari et al. 1998: 24), a comparison is worthwhile of the de-gendered flexibility pattern of German banking call centres to other instances of gendered/gendering organizational change in banking. While in both the UK and Germany, traditional careers in banking have been male-dominated, women have gained considerable ground. In Germany, 50 per cent of banking apprentices, and in recent years also half of the graduates of the further occupational training courses and banking academies have been women. Their share in graduate trainee programmes has increased to just below 50 per cent in the 1990s (Tienari et al. 1998: 29).

During the same period, banking has been an area of major organizational change (Regini et al. 1999). The influence of institutional and regulatory change and the use of information technology have led both to a crossnational convergence of management models and orientations (Leitbilder) such as 'lean banking', and to a persistence of nationally specific actual patterns and practices of reorganization (Tienari et al. 1998; Hildebrandt 1999; Quack and Morgan 2000a). In most countries, reorganization has been characterized by decentralization, internal marketization, a flattening of hierarchies, a diffusion of team working and interdisciplinary project work. Centrally, customer relationships have been recast with a focus on sales and on segmenting customer groups according to their respective value and potential for comprehensive financial services (Batt 2000). These developments led to a differentiation of sales channels. Banks focused their face-toface contact and advisory capacity on promising customers and products while expanding self-service, electronic and telephone banking for others. 
The German banking system has traditionally been based on universal banks offering a comprehensive range of services to different customers (Baethge et al. 1999b; Quack 1999; Morgan and Quack 2000; Quack and Morgan 2000a). Qualification has been based on the German dual system of apprenticeship, with further institutionalized steps of occupational training and strong internal labour markets. In recent years, the recruitment of university graduates and the establishment of trainee programmes has increased. In the 1990s, gradual downsizing and cost-cutting strategies of automation were complemented by a redirection of resources towards investment banking.

In Germany, which lagged behind other countries in these developments, reorganization strategies have often been employed in tentative and contradictory ways. Towards the end of the 1980s, for example, it was received wisdom that the Citibank approach of standardized products and self-service would not be accepted in Germany (Arzbächer et al. 2002). In the 1990s, direct banks were established nevertheless and mass-market banking was outsourced to call centre and internet-based subsidiaries, only to be reintegrated into full-service banks a few years later. The separation and segmentation of service and sales channels has been followed by the establishment of 'multi-channel services'.

Especially the segmentation of customers has led to considerable changes in the product structure, the skills required, and gendered careers in banking. While a traditional German banking clerk developed a deep general knowledge of the business through her apprenticeship, increasingly the training has focused on the selling of standardized products to 'average' private customers with an emphasis on soft and interpersonal skills (Vitols 2003). Karen Shire (2005) reports that - contrary to our call centre findings - face-to-face selling managers still draw on gendered images of deskilling. One manager in a branch office told her, the ideal person for this would be a cosmetics saleswoman rather than a banking clerk: he regarded looks and friendliness as sufficient for selling standardized banking products.

Advising wealthier customers (Vermögenskunden) meanwhile has become the job of financial advisers, either university graduates or graduates of the banking academies. Notably, the shift towards selling has also led to an increase in women's share of branch manager posts and lower and middle management positions (Quack 1997, 1999; Tienari et al. 1998).

Banks' strategies of customer segmentation and diversifying communication channels thus have a variety of gendered outcomes. The downward flexibility of skilled women doing downgraded jobs still features in German banking, but in middle management it has been translated to a higher level than with the routinized clerking of the 1980s. With increasing downsizing and back-office automation in banks, women have improved their skills and moved on to management positions, but to somewhat devalued ones 
under tighter controls. The demands on selling banking services have also increased. Data mining and the standardization of products, which is complemented by continuous innovation, generate computerized sales proposals for specific customers which sales clerks are expected to sell. Sales clerks thus need to communicate and make interactive sense of sales strategies generated elsewhere in the organization (Bienzeisler and Tünte 2003). The traditional banking clerks' expertise and advising capacity is thus replaced, or rather rendered invisible, by a combination of knowledge generated in databases and the supposedly 'interpersonal' skills of convincing a customer of the company's offer. In face-to-face customer contact, managers interpret these demands in a gendered way, drawing on specifically feminine aesthetic and emotional labour (cf. Witz et al. 2003), while in call centres new labour forces come into view.

In this context then, call centres have functioned as experimentation sites for a redefinition of skill and a recomposition of workforces. With the shift towards multi-channel sales, deskilled banking clerks in the branches and socially skilled students and people with non-banking qualifications in the call centres face similarly contradictory demands at work. They compete over the definition of skill and expertise, and indeed, over jobs.

\section{Comparing call centre work and gender in Germany and the UK}

Call centres play distinct parts in the respective economies of Britain and Germany:

With an earlier establishment of call centres Britain is frequently seen as an example for the successful expansion of service employment. In Germany, white-collar work has traditionally been embedded in the specific traditions of occupational training and co-operative industrial relations which define the German model. Call centres represent a strategic challenge to that model. Their expansion has been at the forefront of changes aiming at making employment more flexible in Germany. (Shire, Holtgrewe and Kerst 2002: 2)

A fairly similar gendered employment structure is thus situated in a distinct societal context, and this context helps explain the earlier adoption and wider diffusion of call centres in the UK and US (Bain and Taylor 2002). 'Varieties of capitalism' research (Hall and Soskice 2001) has frequently pointed out how liberal-capitalist societies offer a favourable and enabling institutional context for market-oriented reorganization and process innovation (cf. Lehrer 2001), while such strategies take longer and take a different shape in regulated capitalist societies. 
While both the general labour force participation rate of women and their share of part-time work in Germany are lower than in Britain, ${ }^{8}$ call centres are similarly feminized with two-thirds to 70 per cent women. The actual proportion of women in each call centre varies depending on the business: up to 90 per cent in mail order and outsourced businesses, around 50 per cent in technical hotlines (Bittner et al. 2002; Belt et al. 2002). Especially in outsourced call centres, gender may even vary with the particular campaign or project. The share of female part-timers in German call centres is higher than in Britain (40-50 per cent vs. 27 per cent respectively, according to Belt et al. 2002), though Durbin (in this volume) finds 43 per cent of part-timers in her case studies.

However, British research on gender in call centres predominantly finds a reiteration of traditional gender divisions. Women fill the de-skilled and devalued new service jobs (Jenkins 2004), and they are recruited for their supposed social skills - which often enough turn out to be coping skills (Webster 1996; Tyler and Taylor 2001; Belt 2002; Belt et al. 2002; Thompson and Callaghan 2002), misrecognised as 'natural' or as personality traits. Call centres across industries seem to be comfortable with fairly traditional gendered and gendering ascriptions (Durbin in this volume), while, as we have seen, in Germany gender loses some relevance especially in banks, the most strategically ambitious industry using call centres.

A tentative explanation in line with varieties of capitalism and gender regime could be the following. It is possible that the combination of a market-led gender regime and a commodified female workforce (in the sense of Esping-Andersen 1990) in a liberal market economy still offers enough flexibility even for new, knowledge- and ICT-based organizational forms leaving gendered ascriptions of skill intact. In the context of a regulated economy, however, with a modernized male-breadwinner gender regime, women's limited labour market participation presents dysfunctional limitations when firms aspire to market-driven flexibility. Thus, firms seek to avoid or escape the regulated institutional ensemble and gender regime if and when their market requires patterns of flexibility which are incompatible with the gender regime. While the shift to a public gender regime in a liberal economy typically means an expansion of the flexible female workforce, the case of German banking call centres demonstrates the tensions between the gender regime and the 'new economy' market orientation of firms in a regulated economy.

A complementary explanation hinges on the specificity of the 'new' workforces which supply German banks with a de-gendered type of flexibility (cf. Arzbächer et al. 2002). In Germany, university education generally takes longer than in the UK and courses tend to be less regulated. In recent years, with cuts in state-sponsored grants to students, it has become quite common for students to work long-hour part-time jobs even during the semesters, especially in metropolitan areas with higher costs of living. Due to the 
length of a university education in Germany students present a workforce with just the right combination of retention and volatility - plus they have communicative skills which now can be ascribed to age and lifestyle rather than gender.

In the German banking case, the commodification of students' labour as a potential workforce has overtaken that of women - at least in terms of flexible working times and schedules. The availability of this new workforce may in turn have enhanced firms' perceptions of wider options in the composition of workforces. Thus both reasons, the limited flexibility of women and the increased flexibility of students, are likely interrelated and mutually reinforcing. The restructuring of flexibility in this case emphasizes the tensions and contradictions inherent to a regulated variety of capitalism with a modernized-conservative gender regime faced with the increased strategic options which the new economy offers firms.

\section{Conclusions: gendered banking and de-gendered call centres}

While in other industries, call centres indeed reiterate the gendered paths of Fordist rationalization, the case of banks is the most complex. Theoretically the banking case points to an increasing flexibility in the relationship of organizations and specific industries and the society-wide gender regimes through the utilization of new organizational forms.

In Germany, the established gendered pattern of flexibility consisted of a devaluation of skilled women's work and limited labour market opportunities. Yet, in the case of German banking call centres, the restructuring of organizational flexibility and an increasing market orientation have devalued the capacity for flexibility supplied by women workers in a modernized breadwinner gender regime and shown up its limitations. The traditional forms of gendered working times and labour supply in this new and strategically implemented organizational form become a restriction rather than a resource. The escape of banking call centres from previous regulations through the establishment of independent call centre subsidiaries is also a move away from the previous patterns of gendered and gendering flexibility. Hence, the establishment of a new organizational form de-genders divisions of labour by replacing one flexible but immobile workforce with another even more transitory one.

Both women working part-time and students are workforces whose labour market participation is strongly influenced by the institutions of the welfare state and by culturally embedded norms of appropriate lifestyles and commitments within and outside work. Drawing on gender regimes and gender relations to generate flexibility thus becomes one option among others; organizations and industries can make use of this increased range of options according to their strategic outlook. However, on the symbolic level, the 
semantics of skill and dynamism reiterate the established gender distinctions. We might say that ascriptions and meanings of femininity lose 'practical' relevance while the connotation of masculinity with management and technical expertise is reasserted, only becoming slightly more accessible for women without care responsibilities.

The possibilities of making gender relevant or not (cf. Wilz 2002) then appear to be contingent upon a gender regime's 'fit' with companies' and industries' strategic range and strategic alternatives. Path dependencies and breakaways are both possible within the same industry, and organizations' orientation towards the market leads them to recombine them in the face of perceived options and restrictions. A focus on organizations and their strategies towards their (actual and potential) markets thus adds a promising level of analysis to the effects of changing interrelations between transforming gender regimes and economies.

\section{Notes}

1. The findings presented in this chapter are based on the DFG research project 'Call Centres in between Neo-Taylorism and Customer Orientation' which was conducted by the author as a principal researcher (together with Julia Althoff, Sandra Arzbächer, Hanns-Georg Brose and Christian Kerst) at Duisburg University from 2000-2. Thanks are due to these collabourators, to our interviewees and to the editors and authors of this volume who intensively discussed previous versions and helped to draw out the conclusions presented here. Karen Shire's help with the language and many other things is especially much appreciated. The author is responsible for any remaining errors.

The DFG project involved case studies of seven German call centres (with expert interviews, workplace observations and a survey of 491 call centre agents), plus shorter visits in four additional call centres. Sites were selected in order to cover the range of relevant industries, functions and skill levels. In the sample of call centres there were three banks, three outsourcing/marketing call centres, two call centres in telecommunications and one each in the fields of transport, mail order and health. The type of organization studied ranged from a telephone bank with 700 agents at three sites to a small telemarketing agency with 26 agents. All except for one telecommunications call centre were German-based companies.

2. The notion of escape (Oliver 1991) means a possible response strategy of organizations to institutional pressures. While classic neo-institutionalism focuses on organizations adapting their structures and routines to institutionalized expectations, Oliver explores a variety of strategic responses ranging from escape, avoidance or defiance to strategies of manipulation, influence and control over the environment.

3. For the same reason, the question in our own study was not chiefly gender-related. We thought about call centres as boundary-spanning units in an organizational and functional perspective first. Under conditions of organizational flexibility on the one hand, of a de-standardization of life-courses and gender regimes on the other, we expected the gendered pattern of skill deployment to extend to other segments of the workforce (Gundtoft and Holtgrewe 2000: 197). 


\section{Gendering New Employment Forms}

4. Representative figures for national call centre 'industries' do not exist yet.

5. We did not find any short-hours part-time work (geringfügige Beschäftigung, which is subsidized through lower taxes and social insurance in Germany), and were told by personnel managers that the cost for training CSRs was too high to make it effective.

6. This is roughly in line with recent German microcensus data in which women are found in 33 per cent of management positions and 21 per cent of top management positions (Statistisches Bundesamt 2005: 53).

7. Since the study did not cover long-term developments, I cannot prove that such a homogenization of workforces is indeed a general trend, but managements' interpretations need to be taken at face value.

8. Labour force participation of women aged 15-64 years: 64.5 per cent in Germany, 69.2 per cent in the UK; part-time employment as a proportion of total employment for women: 36.6 per cent in Germany, 40.1 per cent in the UK (OECD 2004a). 